\title{
Effect of Red Onion (Allium cepa var ascalonicum) Skin Ethanolic Extract on the Motility and the Adhesion Index of Pseudomonas aeruginosa and Macrophage Phagocytosis Index
}

\author{
Irma Prasety Ayu Nugraheni' ${ }^{1}$, Derana Widyastika ${ }^{1}$, Sofia Maulida ${ }^{1}$, Heni Susilowati ${ }^{2}$, Alma Linggar \\ Jonarta ${ }^{2 *}$ \\ ${ }^{1}$ Faculty of Dentistry, Universitas Gadjah Mada, Yogyakarta \\ ${ }^{2}$ Oral Biology Department, Faculty of Dentistry, Universitas Gadjah Mada, Yogyakarta
}

\begin{abstract}
Red onion skin (Allium cepa var ascalonicum) contains various ingredients that may function as antibacterial agents against microorganisms, as well as anti-inflammatory and immunomodulator agents for host cells, such as macrophages. Pseudomonas aeruginosa found in the oral cavity is commensal bacteria that may turn into opportunistic pathogen by utilizing its virulence factors such as motility and adhesion to the host cell. The purpose of this study was to investigate the effect of red-onion-skin ethanolic extract towards P. aeruginosa ATCC 9027 on the motility and adhesion ability, furthermore, to know its effect on the macrophage phagocytosis. The research was conducted into three parts of experiment using red-onionskin ethanolic extract. Extract-induced bacterial motility test was carried out on semi-solid media, stained using $0.1 \%$ crystal violet, then the radial length of the bacterial movement was measured. The bacterial adhesion index to buccal cells was calculated after incubated for two hours and stained with Gram stain. Phagocytic activity of the host cells on P. aeruginosa was done by exposing the extract to the mouse peritoneal macrophages, then the phagocytosed bacteria were counted after Giemsa staining. Statistical test results from the three experiments showed significant differences between the test groups compared to the control groups $(\mathrm{p}<0.05)$. It was concluded that the red onion-skin ethanolic extract not only affects $P$. aeruginosa by reducing swarming motility and preventing bacterial adhesion to buccal epithelial cells, but also induces the host cells by increasing the ability of macrophage phagocytosis to these bacteria.

Key words: Red-onion-skin ethanolic extract, Pseudomonas aeruginosa ATCC 9027, swarming motility, Adhesion Index, Macrophage Phagocytosis Index.
\end{abstract}

\section{INTRODUCTION}

Pseudomonas aeruginosa is a Gramnegative, motile, rod-shaped bacteria that lives in an aerobic and anaerobic environment (Burrows, 2012), and is a cause of nosocomial infections because it may turn from oral commensal bacteria to opportunistic pathogen (Lister et al., 2009). Under normal circumstances, $P$. aeruginosa can be found in subgingival plaque, gingival sulcus epithelium and buccal epithelial cells (Caldas et al., 2015). In certain conditions these bacteria may turn into pathogens and worsen the infection of the oral cavity. Pseudomonas aeruginosa can be found in patients with chronic apical periodontitis (Brooks et al., 2010; Sutasmi et al., 2014). Pseudomonas aeruginosa has flagella and type IV pili (Conrad et al., 2011) which play a role in swarming motility and as a virulence factor (Wu et al., 2011) by binding to epithelial cells. PilA protein in pili binds to glycolipids and glycoproteins asialoGM1 and GM2 (Albrecht et al., 2002; Johnson et al., 2011), whereas PILY1 binds to calcium in the epithelial cell integrins (Johnson et al., 2011).

*Corresponding author: Alma Linggar Jonarta

Email : almajonarta@ugm.ac.id
The oral cavity is the first barrier to the invasion of various kinds of microorganisms. When P. aeruginosa turn into pathogenic bacteria, they may suppress the expression of immune defense, one of which is by producing pyocyanin (Evans et al., 2008). Pseudomonas aeruginosa also has a T3SS protein which contains exoenzyme S (ExoS), exoenzyme $U$ (ExoU) and exoenzyme $T$ (ExoT) which inhibit phagocytosis in macrophages (Lavoie et al., 2011).

Red onion (Allium cepa var ascalonicum) skin has not been optimally utilized. It contains antibacterial and immunomodulatory agents such as flavonoid and quercetin (Elberry et al, 2014). Quercetin enhances the ability of macrophages phagocytosis, by increasing IL-12 production (Setyawan, 2015), also inhibits PILY1 protein so it cannot bind to calcium in epithelial cells and interfere with the process of bacterial adhesion. Moreover, quercetin from onion skin inhibits bacterial motility by altering the membrane potential of bacterial cells, affecting the main proton pump so that it cannot produce energy to transport hydrogen ions from the cytoplasm to the outside of the cell (Mirzoeva et al., 1997). In 
addition, polyphenol binds to P. aeruginosa pili and inhibits bacterial adhesion (Johnson et al., 2011). The aims of the study were to investigate the effects of red onion skin ethanolic extract on $P$. aeruginosa motility and its attachment to buccal epithelial cells, furthermore, to study the ability of macrophage phagocytosis against $P$. aeruginosa in vitro.

\section{METHODOLOGY Materials}

Red onion harvested from the agriculture area in Samas, Bantul, DIY Province, Indonesia, had been determined as Allium cepa var ascalonicum species at the Laboratory of Plant Systematics, Faculty of Biology, Universitas Gadjah Mada (No. 01038 / S.Tb / IV / 2017). Pseudomonas.aeruginosa ATCC 9027 was purchased from Microbiologics $₫$ Inc, Amerika. Epithelial cells were collected from a human volunteer buccal mucosa using cytobrush, whereas macrophage cells were isolated from mouse peritoneum makrofag (MPM). This research obtained three ethical clearance certificates from the Research Ethics Committee of the Faculty of Dentistry, Universitas Gadjah Mada Indonesia No. 001289/ KKEP/ FKG-UGM/ EC/ 2018, No. 001292/ KKEP/ FKG-UGM/ EC/ 2018 and 001293/ KKEP/ FKG-UGM/ EC/ 2018.

\section{Methods}

Pseudomonas.aeruginosa ATCC 9027 were cultured in liquid BHI media, incubated at $37^{\circ} \mathrm{C}$ for 24 hours, washed by adding $0.9 \% \mathrm{NaCl}$, then centrifuged 2 times for 10 minutes $(5,000 \mathrm{rpm})$ (Wolska et al., 2005). $\mathrm{NaCl}$ solution was added to achieve $0.5 \mathrm{McF}$ arland standard or $10^{8} \mathrm{CFU} / \mathrm{ml}$ of bacterial concentration (Limsuwan et al., 2014).

The onion skin was extracted by ethanol maceration method (Skerget et al., 2007). The extract was diluted in sterile distilled water, centrifuged $(10,000 \mathrm{rpm})$ and filtered using nylon membrane syringe filter $0,45 \quad \mu \mathrm{m}$ (Taweechaisupapong et al., 2004). The inhibitory minimum concentration of red onion skin extract against $P$. aeruginosa was $10 \%$.

Macrophages were isolate from Balb/C mice ages 6-8 weeks. After the mice were sacrificed under anesthesia, the peritoneal layer was injected by $10 \mathrm{ml}$ of cold RPMI medium followed by the aspiration of peritoneal fluid. The aspirate was centrifuged at $1,200 \mathrm{rpm}$ at $4^{\circ} \mathrm{C}$ for 10 minutes. The supernatant layer was discharged, then $3 \mathrm{ml}$ of complete RPMI medium containing 10\% v/v FBS was added. After calculating for cell viability, the cells were resuspended in complete RPMI medium $\left(2.5 \times 10^{6} / \mathrm{ml}\right)$. Two hundred $\mu \mathrm{l}$ of cell suspension ( $5 \times 10^{5}$ cells) was then cultured in a 24 well plate on the round coverslips followed by incubation in $5 \% \mathrm{CO} 2$ incubator at $37^{\circ} \mathrm{C}$ for 30 minutes. One ml of complete RPMI medium was added into each well, then incubated for 2 hours. After washed using RPMI twice, $1 \mathrm{ml}$ of complete RPMI medium was added and the cells was re-incubated for 24 hours before treatment (Prayitno et al., 2016)

Swarming motility test was carried out on the negative control group $(100 \mu \mathrm{L}$ of sterile distilled water) and treatment group (100 $\mu \mathrm{L}$ of $2.5 \%, 5 \%$, or $10 \%$ extract concentration), six replications of each group. A hundred $\mu \mathrm{L}$ sterile distilled water or $2.5 \%, 5 \%, 10 \%$ of onion skin extract concentration were added into the tubes, followed by the adding of $200 \mu \mathrm{L}$ of bacterial cells. The suspensions were incubated at $37^{\circ} \mathrm{C}$ for 2 hours using a shaking water bath. Bacterial suspensions were then cultured on $5 \%$ Bacto Agar semi-solid media, incubated at $37^{\circ} \mathrm{C}$ for 24 hours, stained using $0.1 \%$ crystal violet then washed (Deaziel et al., 2001). The average length of radian movement of bacteria on four different sites was measured.

Adherence test. Two groups were used in this research part, control (sterile distilled water) and treatment groups consisted of 3 concentrations of red onion skin extracts $(2,5 \%$, $5 \%$, or $10 \%$ ). Epithelial cells were suspended in physiological saline, centrifuged, and adjusted for the cell concentration of $2 \times 10^{5} \mathrm{sel} / \mathrm{mL}$ (Wolska et al., 2006). A hundred $\mu \mathrm{L}$ of sterile distilled water or 3 concentrations of onion skin extract solution were put on the tubes. In each test tube was added $200 \mu \mathrm{L}$ of bacterial cell suspension containing $2 \times 10^{7}$ cells (concentration of $108 \mathrm{CFU} / \mathrm{mL}$ ) and $200 \mu \mathrm{L}$ of buccal mucosal epithelial cells containing $2 \times 10^{5}$ cells / mL. The suspension was then incubated at $37^{\circ} \mathrm{C}$ for 2 hours in the shaking water bath (Wolska et al., 2006) then washed by twice centrifugation at 3,000 rpm for 15 minutes to remove unattached bacteria. The samples were fixed on the glass slides and stained using Gram method. The adhesion index was done by calculating the number of bacteria attached to buccal cells using a light microscope 1000x magnification (Taweechaisupapong et al., 2005). Calculation of the adhesion index according to Sumarno (2000).

Macrophage phagocytosis test was conducted in 2 sample groups, control groups consist of positive (Imboost $($ ) and negative control (complete RPMI) group, and treatment groups $(2,5 \%, 5 \%$, or $10 \%$ of red onion skin extract concentration). Two hundred $\mu \mathrm{L}$ of each solution was added into the wells containing $5 \times 10^{5}$ macrophages suspension which was then incubated for 4 hours. The wells were washed with 
Table I. LSD Post Hoc test of Three Concentrations of Red Onion skin extract exposure on swarming motility of $P$. aeruginosa compared to the negative control

\begin{tabular}{cccccc}
\hline & \multirow{2}{*}{ Negative Control } & \multicolumn{3}{c}{ Treatment } \\
\cline { 3 - 6 } Negative Control & - & $\mathbf{2 , 5 \%}$ & $\mathbf{5 \%}$ & $\mathbf{1 0 \%}$ \\
\multirow{3}{*}{ Treatment } & $\mathbf{2 , 5 \%}$ & 0,20 & 0,20 & 0,00 & 0,00 \\
& $\mathbf{5 \%}$ & 0,00 & - & 0,00 & 0,00 \\
& $\mathbf{1 0 \%}$ & 0,00 & 0,00 & - & 0,19 \\
\hline
\end{tabular}

RPMI, then $10^{8} \mathrm{CFU} / \mathrm{ml}$ P. aeruginosa was added, and re-incubated for 60 minutes. Samples were washed with PBS three times, then added methanol for 30 seconds, followed by 30 minutes of Giemsa staining, washed with distilled water and finally dried. The calculation of Phagocytosis Index (IF) were performed by observing the number of bacterial phagocytosed by macrophage on the coverslip under a 1000x magnification microscope. The calculation of Phagocytosis Index referred to the formula of Jensch-Junior et al., (2006).

\section{RESULTS AND DISCUSSION}

The radial measurements of bacterial swarming motility showed a reduction in bacterial motility along with the increase of red onion skin extract concentration (Figure 1). The bacterial motility of the treatment group showed a lower value compared to the negative control group. This indicated the ability of red onion skin extract to reduce the motility of $P$. aeruginosa ATCC 9027.

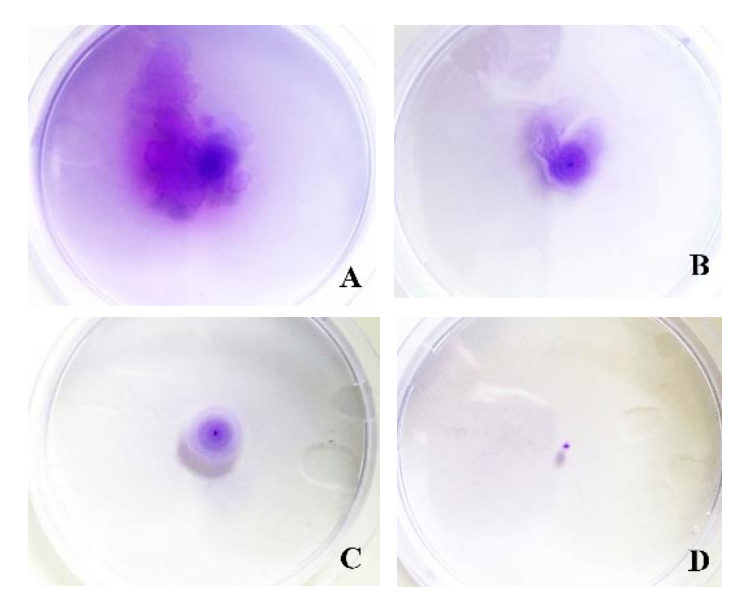

Figure 1. P. aeruginosa swarming motility on semisolid media showed that the largest radiant of swarming motility of $P$. aeruginosa was the negative control group (A), followed by the exposure group extract concentration of $2.5 \%$ (B), 5\% (C), and the smallest one was extract $10 \%$ (D). Cystal violet staining.
One-way ANOVA test showed a significant difference between each treated group $(p=0.00)$ that indicated the red onion skin extract affected the motility of P. aeruginosa ATCC 9027. Moreover, Post Hoc LSD test performed on the (Table I) below showed the extract with a concentration of $5 \%$ as well as $10 \%$ had the equivalent ability to inhibit the motility of $P$. aeruginosa, while the extract concentration of $2.5 \%$ and negative control failed to inhibit bacteria motility.

Flagella and type IV pili are used to move along semi-solid surfaces (Conrad et al., 2011). Hyper flagellation causes bacterial movement namely swarming motility that occurs in the media under the conditions of low water content so that the bacteria move in a clustered or coordinated manner (Rashid and Kornberg, 2000). Swarming motility is described as a coordinated and rapid bacterial movement (O'toole and Kolter, 1998) and also increases bacterial virulence (Hancock et al., 2007). Potential cell membrane may disturbed by the presence of quercetin that will cause disruption of ATP synthesis, therefore the cells do not produce enough energy for proton pump to transport hydrogen ions outside the cells (Campbell et al., 2003). Moreover, tannin compounds block swarming motility by decreasing the production of rhamnolipid (O'may and Tufenkji, 2011). The decrease in rhamnolipid production causes high stress on the cell surface which causes bacterial flagella to become stiff and the failure on swarming motility (Oura et al., 2015)

Pseudomonas aeruginosa produces biosurfactant in the form of rhamnolipid which plays a role in the surface hydrophobicity of bacterial cells (Sotirova et al., 2009). At the early stages of the attachment process, the rise of rhamnolipid concentration causes lipopolysaccharide leaves the cell membrane and be replaced with phospholipids. The condition increases the cell surface hydrophobicity of $P$. aeruginosa (Al-tahhan et al., 2000) that mediates the process of bacterial adhesion to the cell surface (Harmsen et al., 2017). Tannin compounds from 
the extract may reduce rhamnolipid production of the bacteria and the surface hydrophobicity of bacterial cells, therefore cause the inhibition of adhesion.

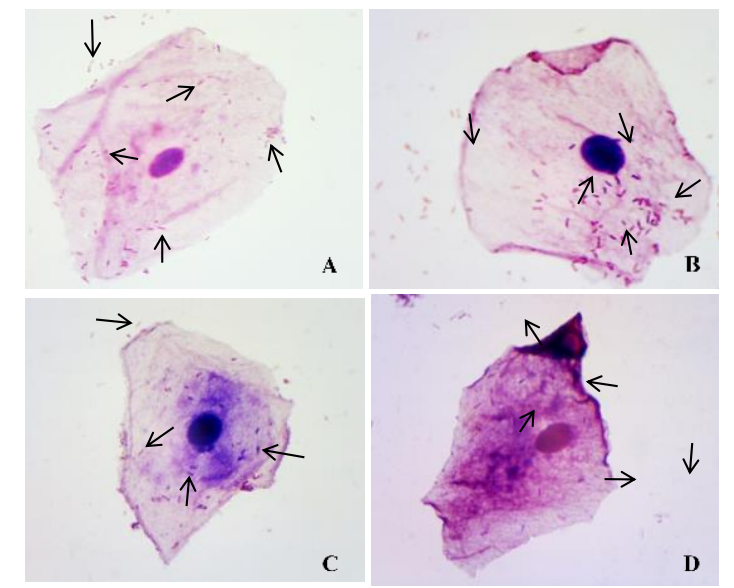

Figure 2. The extract of red onion skin affected the adhesion capability of $P$. aeruginosa onto the epithelial buccal cells. The least number of bacteria attached to the cells was performed on extract concentration of $10 \%$ group (D) and showed more bacteria along the reduced concentration of the extract: $5 \%$ (C) and 2.5\% (B); whereas the biggest number of attached bacteria was on negative control (A) group. Arrows indicated P. aeruginosa. Gram staining on 400x magnification.

The exposure of the red onion skin extract onto the bacteria showed that the higher the concentration of red onion skin extract, the lower the bacterial adhesion index (Figure 2).

Table II. Mean and Standard Deviation of Adhesion Index of P. aeruginosa ATCC 9027 after Exposed to Three Concentration of Red Onion Skin Extracts onto Buccal Epithelial Cells

\begin{tabular}{lc}
\hline \multicolumn{1}{c}{ Groups } & Mean \pm SD \\
\hline Negative Control & $74.42 \pm 1.78$ \\
Red onion extract 2,5\% & $63.60 \pm 1.89$ \\
Red onion extract 5\% & $22.86 \pm 0.45$ \\
Red onion extract 10\% & $14.88 \pm 0.52$ \\
\hline
\end{tabular}

The bacterial adhesion index in treated group showed a lower value compared to the negative control group. The lowest adhesion index value was in the $10 \%$ extract concentration group (Table II).

The obtained data of adhesion index was normal but not homogenic, therefore Welch's ANOVA as well as Games-Howell test were performed. The result of the tests showed that there was a very significant $(\mathrm{p}=0.00)$ difference on adhesion index in all groups. It was indicated that the exposure of red onion skin extract significantly prevented the adhesion of $P$. aeruginosa ATCC 9027 onto buccal mucosal epithelial cells.

Quercetin compound in red onion skin binds PilY1, the protein of pili structure, so that PilY1 loses the ability to bind to calcium ions from integrins in epithelial cells and disrupt the process of bacterial adhesion (Johnson et al., 2011). In addition, polyphenol compounds bind to the pili, thereby disrupting bacterial adhesion to the surface of epithelial cells and inhibiting biofilm formation (Krachler and Orth, 2013).

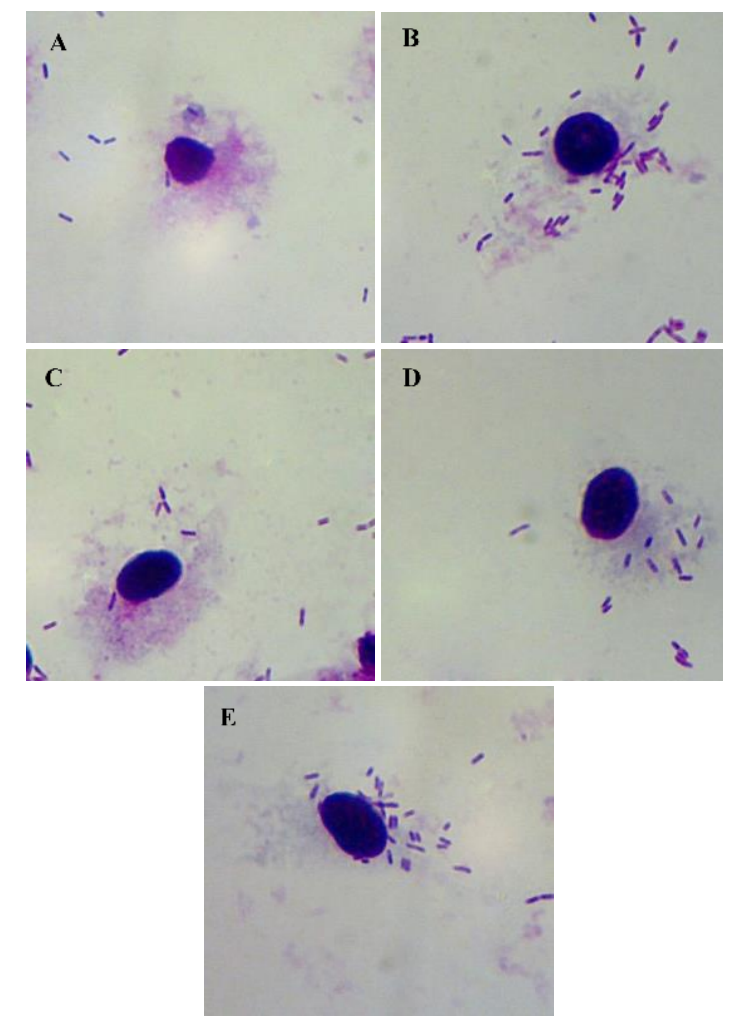

Figure 3. The extract of red onion skin increased the phagocytosis potential of mouse peritoneal macrophage on $P$. aeruginosa. Macrophage phagocytosis on $P$. aeruginosa increased along the increase of extract concentrations of $2.5 \%$ (C), $5 \%$ (D) and 10\% (E). The positive control group (B) showed the high macrophage phagocytosis ability, on the contrary, negative control (A) was much lower. Giemsa staining on 400x magnification.

The extract of red onion skin was not only reduced the capability of $P$. aeruginosa ATCC 9027 virulence factors, but also improved the phagocytosis potential of mouse peritoneal macrophages. The capability of macrophage phagocytosis along with the increase of the red onion skin extract concentrations (Figure 3). 
Table III. Mean and Standard Deviation of Macrophage Phagocytosis Index towards $P$. aeruginosa ATCC 9027 after Exposed to Three Concentration of Red Onion Skin Extracts

\begin{tabular}{lc}
\hline \multicolumn{1}{c}{ Groups } & Mean \pm SD \\
\hline Negative Control & $2.24 \pm 0.13$ \\
Red onion extract 2,5\% & $5.68 \pm 0.24$ \\
Red onion extract $5 \%$ & $8.32 \pm 0.24$ \\
Red onion extract $10 \%$ & $12.37 \pm 0.37$ \\
Positive Control & $13.41 \pm 0.22$ \\
\hline
\end{tabular}

Phagocytosis index of the positive control (Imboost $®$ ) group, as well as the red onion skin extract concentration of $2.5 \%, 5 \%$, and $10 \%$ groups showed higher results than the negative control group (Table III). One-way ANOVA test resulted significant difference in phagocytosis index in all groups $(\mathrm{p}=0.00)$. Further, LSD Post Hoc test showed significant differences between treated groups compared to negative or positive control groups $(p=0.00)$. This indicated that the red onion skin extract might increase the potential of macrophages to phagocyte $P$. aeruginosa ATCC 9027.

The results of this study are in accordance with previous research conducted by Elberry et al., (2014) that red onion skin may act as an immunomodulator. Phenol, as well as quercetin in red onion skin increases IL-2 production (Dewanti et al., 2012; Rauf et al., 2016). This cytokine plays an important role in activating Th1 lymphocytes that secretes IFN- $\gamma$ so that increases phagocytic activity of macrophages (Ulfah et al., 2017). Flavonoids may induce mitogen activated protein kinase (MAPK) activity which triggers the activation of nuclear factor-kappa $\mathrm{B}(\mathrm{NF}-\kappa \mathrm{B})$ and increase cytokine production. Activated NF- $\kappa B$ regulates inflammatory mediators, such as TNF- $\alpha$ that activates Th1 cells, thereby increasing macrophage activity (Hidayat, 2015).

Although in this study the ethanolic extract of red onion skin had not been isolated to the level of active ingredients, the exposure effects of the extract in reducing the ability of $P$. aeruginosa motility and its adhesion to buccal cells, as well as increasing the phagocytic activity of macrophages clearly supported and proved those previous studies.

\section{CONCLUSION}

The conclusion of the study is red onion skin extract not only impairs $P$. aeruginosa virulence factors, by reducing motility and preventing bacterial adhesion to buccal epithelial cells, but also increases the ability of macrophages phagocytosis to these bacteria.

\section{ACKNOWLEDGMENT}

This study is the synthesis of the undergraduate final projects of the first three authors mentioned above.

\section{REFERENCES}

Albrecht, M.T., Wang, W., Shamova, O., Lehrer, R.I., \& Schiller, N.L., 2002, 'Binding of protegrin1 to Pseudomonas aeruginosa and Burkholderia cepacia', Respir. Res., 3(1), 111.

Al-tahhan, R.A., Sandrin, T.R., Bodour, A.A., Maier, R.M., 2000, 'Rhamnolipid-induced removal of lipopolysaccharide from Pseudomonas aeruginosa: effect on cell surface properties and interaction with hydrophobic substrates', Appl. Environ. Microbiol., 66(8), 3262-3268.

Brooks, G. F., Jawetz, E., Melnick, J. L., \& Adelberg, E. A. (2010). Jawetz, Melnick, \& Adelberg's medical microbiology. New York: McGraw Hill Medical.

Burrows, L.L., 2012, 'Twitching motility: type IV pili in action', Annu. Rev. Microbiol, 66, 493520.

Caldas, R.R., Gall, L., Revert, K., Rault, G., Virmaux, M., \& Gouriou, S., 2015, 'Pseudomonas aeruginosa and periodontal pathogens in the oral cavity and lungs of cystic fibrosis patients: a case-control study', J. Clin. Microbiol., 53(6),1898-1907.

Campbell, N.A., Reece, J.B., \& Mitchell, L.G., 2003, Biology, $5^{\text {th }}$ ed., Benjamin/Cummings, Menlo Park, CA.

Colombo, A.V, Barbosa, G.M., Higashi, D., Micheli, G., Rodrigues, P.H., \& Simionato, M.R.L., 2013, 'Quantitative detection of Staphylococcus aureus, Enterococcus faecalis and Pseudomonas aeruginosa in human oral epithelial cells from subjects with periodontitis and periodontal health', J. Med. Microbiol., 62, 1592-1600

Conrad, J.C., Gibiansky, M.L., Jin, F., Gordon, V.D., Motto, D., Mathewson, M.A., Stopka, W.G., Zelasko, D.C., Shrout, J.D., \& Wong, G.C., 2011, 'Flagella and pili-mediated nearsurface single-cell motility mechanisms in $P$. aeruginosa', Biophys. J, 100(7), 1608-1616

Deaziel, E., Comeau, Y., Villemur, R., 2001, 'Initiation of biofilm formation by Pseudomonas aeruginosa 57RP correlates with emergence of hyperpiliated and highly adherent phenotypic variants deficient in 
swimming, swarming, and twitching motilities', J Bacteriol, 183(4), 1195-1204.

Dewanti, T., Sukardiman, Agus, D., \& Darmanto, W., 2012, "The immunomodulatory effect of Mesona palustris BL extract on mice carcinogenesis', J. Teknol. dan Industri Pangan, 23(1), 29-35.

Elberry, A. A., Mufti, S., Al- Maghrabi, J., Sattar, E. A., Ghareib, S. A., Mosli, H. A., \& Gabr, S. A., 2014, 'Immunomodulatory effect of red onion (Allium cepaLinn) scale extract on experimentally induced atypical prostatic hyperplasia in wistar rats', Mediators Inflamm., 2014, 1-13. Article ID 640746, https://doi.org/10.1155/2014/640746

Evans, E. A., Kawli, T., \& Tan, M. W., 2008, 'Pseudomonas aeruginosa suppresses host immunity by activating the DAF-2 insulinlike signaling pathway in Caenorhabditis elegans', PLoS Pathog, 4(10), 1-18

Hancock, R.E.W., Overhage, J., Lewenza, S., \& Marr, A.K., 2007, Identification of genes involved in swarming motility using a Pseudomonas aeruginosa PA01 mini-Tn5-lux mutant library, J. Bacteriol., 189(5), 2164-2169.

Harmsen, M., Yang, L., Pamp, J., Tolker-nielsen, T., \& Tolker-nielsen, C.T., 2010, 'An update on Pseudomonas aeruginosa biofilm formation, tolerance, and dispersal', Immunol. Med. Microbiol., 59, 253-268.

Hidayat, R., 2015, Agonis Peroxisome Proliferator Activator Receptor (PPAR) $\gamma$ reduced the level of anti-inflammatory cytokines TGF- $\beta$ dan IL-10 on wistar rat vascular inflammation model', Sains Medika, 2(3), 291-296.

Jensch-Junior, B.E., Pressinotil, N., Borges, J.C.S. \& Cunha da Silva, J.R.M., 2006, 'Characterization of macrophage phagocytosis of the tropical fish Prochilodus scrofa (Steindachner, 1881)', Aquaculture, 251, 509-515

Johnson, M.D.L., Garrett, C.K., Bond, J.E., Coggan, K.A., Matthew, C., \& Redinbo, M.R., 2011, 'Pseudomonas aeruginosa PilY1 binds integrin in an RGD- and calcium-dependent manner', PLos One, 6(12), 1-8.

Krachler, A.M., \& Orth, K., 2013, 'Targeting the bacteria-host interface: strategies in antiadhesion therapy', Virulence, 4(4), 284-94.

Lavoie, E. G., Wangdi, T., \& Kazmierczak, B. I., 2011, 'Innate immune responses to Pseudomonas aeruginosa infection', Microbes Infect, 13(14), 1-21.

Limsuwan, S., Homlaead, S., Watcharakul, S., Chusri, S., Moosigapong, K., Saising, J., \& Voravuthikunchai, S.P., 2014, 'Inhibition of microbial adhesion to plastic surface and human buccal epithelial cells by Rhodomyrtus tomentosa leaf extract'. Arch Oral Biol, 59(12), 1256-1265.

Lister, P. D., Wolter, D. J., \& Hanson, N. D., 2009, Antibacterial - resistant Pseudomonas aeruginosa: clinical impact and complex regulation of chromosomally encoded resistance mechanisms, Clin. Microbiol, Rev, 22(4), 582-610.

Mirzoeva, O.K., Grishanin, R.N., \& Calder, P.C., 1997, 'Antimicrobial action of propolis and some of its components: the effects on growth, membrane potential and motility of bacteria', Microbial. Res., 152, 239-246

O'toole, G.A., \& Kolter, R., 1998, 'Initiation of biofilm formation in Pseudomonas aeruginosa WCS365 proceeds via multiple, convergent signaling pathways: a genetic analysis, $\mathrm{Mol}$. Microbiol., 28(3), 449-461.

O’May, C., \& Tufenkji, N., 2011, The swarming motility of Pseudomonas aeruginosa is blocked by Cranberry proanthocyanidins and other tannin-containing materials', Appl. Environ. Microbiol. 77(9), 3061-3067.

Oura, H., Tashiro, Y., Toyofuku, M., et al., 2015, Inhibition of Pseudomonas aeruginosa swarming motility by 1-naphthol and other bicyclic compounds bearing hydroxyl groups. Appl. Environ. Microb., 81(8), 28082818.

Prayitno, A., Fitria, M. S., \& Elmanda, A. Y., 2016, 'Tumoricidal activation of macrophages using Jatropha curcas leaf extract: as a proxy for the treatment of cancer, Immunome Res, 12(1), 1-3.

Rashid, M. H., \& Kornberg, A., 2000, 'Inorganic polyphosphate is needed for swimming, swarming, and twitching motilities of Pseudomonas aeruginosa', Proc Natl Acad Sci, 97(9), 4885-4890.

Rauf, A., Haeria, \& Anas, D. D., 2016, ' The immunostimulant effect of Katuk leaf fraction (Sauropus androgynus L. MERR.) on the phagocytosis activity and capacity of male mice (mus musculus) macrophage', JF FIK UINAM, 4(1), 9-15.

Setyawan, A. B., 2015, 'The effectivity of kejibeling leaves extract in increasing macrophage phagocytosis and the production of macrophage ROI - an experimental study on Staphylococcus aureus-infected Swiss mice', JSK, 1(4), 195-201.

Skerget, M., Majhenie, L., \& Bezjak, M., 2009, 'Antioxidant, radical scavenging and antimicrobial activities of red onion (Allium 
cepa L) skin and edible part extract's, Chem. Biochem. Eng. Q. 23(4), 435-444

Sotirova, A., Spasova, D., Vasileva-Tonkova, E., \& Galabova, D., 2009, 'Effects of rhamnolipidbiosurfactant on cell surface of Pseudomonas aeruginosa', Microb. Res. 164(3), 297-303.

Sumarno. 2000. Molecular characterization of adhesion proteins Vibrio cholera 01 M094 and its receptor protein in white rat small intestine epithelial cells (Wistar). A pathogenesis study of E. cholerae 01 M094, Thesis, Program Pasca Sarjana, Universitas Airlangga Surabaya.

Sutasmi, Y. \& Natsir, N., 2014, 'Bacterial identification on chronic apical periodontitis tooth root canal', Dentofasial, 13(3),182-185

Taweechaisupapong, S., Choopan, T., Singhara, S., Chatrchaiwiwatana, S., \& Wongkham, S., 2005, 'In vitro inhibitory effect of Streblus asper leaf-extract on adhesion of Candida albicans to human buccal epithelial cells', J.
Eth. Pharm., 96, 221-226.

Ulfah, M., Cahyani, V. S. N., \& Kinasih, I., 2017, 'The effect of Annona muricata L. infuse tea on the macrophage phagocytosis activity and lymphocyte proliferation of Hepatitis B vaccine-induced Balb/C mice', Momentum, 13(2), 63-71.

Ulum, A. N., Ulfah, M., \& Sasmito, E., 2016, 'Immunomodulator activity test of fermented Kombucha yeast black tea on Balb Balb/c mice phagocytosis in vitro', JSFK, 13(2): 24-31.

Wolska, K., Zabielska, K., \& Jakubczak, A., 2006, 'Effect of neuraminidase on adherence of Pseudomonas aeruginosa to human buccal epithelial cells. Inhibition of adhesion by monosaccharides'. Polish J. Microbiol, 55(1), 43-48.

Wu, H., Lee, B., Yang, L., Wang, H., Givskov, M., Molin, S., Hoiby, N., \& Song, Z., 2011, 'Effects of ginseng on Pseudomonas aeruginosa motility and biofilm formation, Immunol Med Microbial, 62, 49-5. 